\title{
Thalidomide: efficacy and side effects in juvenile idiopathic arthritis
} (JIA)

\author{
MG Alpigiani ${ }^{* 1}$, Doria Lamba L ${ }^{2}$, M Haupt ${ }^{1}$, A Calcagno ${ }^{1}$, E Poggi ${ }^{1}$, P Salvati ${ }^{1}$ \\ and R Lorini ${ }^{1}$
}

\author{
Address: ${ }^{1}$ Institute G. Gaslini, Department of Pediatrics, University of Genova, Genova, Liguria, Italy and ${ }^{2}$ Institute G. Gaslini, Pediatric \\ Neuropsychiatry Unit, University of Genova, Genova, Liguria, Italy \\ * Corresponding author
}

\author{
from I5th Paediatric Rheumatology European Society (PreS) Congress \\ London, UK. 14-17 September 2008 \\ Published: 15 September 2008 \\ Pediatric Rheumatology 2008, 6(Suppl I):P70 doi:I0.I I86/I546-0096-6-SI-P70
}

This abstract is available from: http://www.ped-rheum.com/content/6/SI/P70

(c) 2008 Alpigiani et al; licensee BioMed Central Ltd.

\section{Background}

Thalidomide is an immunomodulating agent; although its action mechanisms are not fully understood, many authors have described its anti-inflammatory and immunosuppressive properties with Peripheral Neuropathy $(\mathrm{PN})$ as a significant side effect, which may limit its clinical use.

\section{Methods}

We describe a patient with JIA at systemic onset, partial responding to etanercept, who presented a good control of articular symptoms after thalidomide, but showed PN after 16 months of therapy.

\section{Results}

Our patient, boy, 19 years old, $63.5 \mathrm{~kg}$ ( $50^{\circ}$ centile), 161 $\mathrm{cm},\left(3^{\circ}\right.$ centile), is affected by JIA, diagnosed at the age of 7 years. Since he presented many acute phases of illness, though on therapy with immunosuppressant (methotrexate $10 \mathrm{mg} / \mathrm{m} 2 /$ week), steroid and NSAID, in 2001 we introduced an anti-TNF drug (etanercept $0.5 \mathrm{mg} / \mathrm{kg} /$ twice a week) while reducing progressively steroid dose. However the patient showed still numerous articular acute phases. We decided to associate thalidomide $(100 \mathrm{mg} /$ die). After two months, the boy showed an improvement of the articular symptoms. After six months JIA was in remission. After 16 months of thalidomide therapy, he presented electrophysiological $\mathrm{PN}$, without clinical signs; we decided to stop the thalidomide therapy. Now, after 3 years of thalidomide suspension, no acute phases of JIA were observed and an electrophysiological improvement of PN was confirmed.

\section{Conclusion}

Our data show that thalidomide can be administered in children with resistant forms of JIA, but a long-term administration can significantly increase the risk of neurotoxicity [1]. A regular follow-up every 3 months is necessary to identify and monitor possible side effects

\section{References}

I. Priolo T, et al: Childhood thalidomide neuropathy: a clinical and neurophysiologic study. Pediatr Neurol 2008, 38: I96-199. 